\title{
O Eu e o Outro no mito freudiano da fundação da cultura
}

The I and the Other in the Freudian myth of the foundation of culture

El Yo y el Otro en el mito freudiano de la fundación de la cultura

\author{
Leônia Cavalcante Teixeira* \\ Jacqueline de Oliveira Moreira*
}

\begin{abstract}
Resumo
Este texto objetiva discutir a constituição do sujeito e do coletivo com base no tema da alteridade. $\mathrm{O}$ tema será trabalhado com base no texto freudiano Totem e tabu, pois o consideramos como nuclear para as análises acerca da gênese da cultura e da civilização, particularmente em relação à fratria. Inicialmente, discutimos o conceito de alteridade, tendo como referencial teórico a filosofia de Lévinas. A seguir, o acento recai na leitura freudiana de Totem e Tabu, na qual são ressaltados os lugares fundamentais do Pai, da Lei, da fratria e das leis que acordam a convivência entre os semelhantes, sendo destacadas as contribuições lacanianas. Concluímos que a alteridade constitui conceito nuclear nas abordagens acerca do humano e de seus destinos singulares e sociais, podendo ser nefastos os efeitos do aniquilamento do Outro e do outro.
\end{abstract}

Palavras-chave: Alteridade. Psicanálise. Filosofia.

\begin{abstract}
This essay intends to discuss the constitution of the subject and the collective, taking the theme of alterity as a starting point. This theme based on the Freudian text Totem and taboo, as we consider the latter to be of central importance to the analyses of the genesis of culture and civilization, particularly regarding phratry. Initially, we discuss the concept of alterity, taking as a theoretical point of reference the philosophy of Lévinas. Then, the focus of the essay shifts to Freud's Totem and Taboo, in which we highlight the fundamental roles of the Father, the Law, phratry and the laws that rule coexistence among corresponding bodies, especially highlighting the lacanian contributions. We conclude that alterity is the central concept in the approach of mankind and its
\end{abstract}

\footnotetext{
Doutora em Saúde Pública pela UERJ, professora do Programa de Pós-graduação em Psicologia (filiado à ANPEPP) (Unifor), bolsista PQ 2, psicanalista. Endereço residencial: Rua Alfeu Aboim, 55 - Papicu, Fortaleza-CE. CEP: 60175-375. Telefone: (85) 3234-1299. E-mails: leoniat@unifor.br, leoniat@uol.com.br.

** Doutora em Psicologia Clínica pela PUC-SP, mestra em Filosofia pela UFMG, professora do Programa de Pós-graduação em Psicologia da PUC-MG (filiado à ANPEPP), bolsista PQ 2, psicanalista. Endereço: Rua Congonhas, 161 - São Pedro, Belo Horizonte-MG. CEP 30.330-100. Telefone: (31) 3223-3951. E-mail: jackdrawin@yahoo.com.br.
} 
singular and social destinies, and that the adverse effects of annihilation of the Other and of the other can be.

Keywords: Alterity. Psychoanalysis. Philosophy.

\section{Resumen}

Este texto objetiva discutir la constitución del sujeto y de lo colectivo a partir del tema de la alteridad. El tema será trabajado a partir del texto freudiano "Tótem y Tabú", ya que lo consideramos nuclear para los análisis acerca de la génesis de la cultura y de la civilización, particularmente en relación a la fratria. Inicialmente, discutimos el concepto de alteridad teniendo como referencial teórico la filosofía de Lévinas. A continuación, el texto pone énfasis en la lectura freudiana de Tótem y Tabú, en que son resaltados los lugares fundamentales del Padre, de la Ley, de la fratria y de las leyes que acuerdan la convivencia entre los semejantes, destacándose las contribuciones lacanianas. Concluimos que la alteridad constituye concepto nuclear en los abordajes acerca de lo humano y de sus destinos singulares y sociales, pudiendo ser nefastos los efectos del aniquilamiento del Otro y de lo otro.

Palabras clave: Alteridad. Psicoanálisis. Filosofía.

\footnotetext{
Considerando a amplitude do tema da relação entre o eu e o outro, pretendemos discuti-la, neste artigo, com base na reflexão freudiana sobre a origem da cultura, anunciada no texto Totem e tabu (1976d). Consideramos que, no mito freudiano da origem da cultura, encontraremos uma reflexão sobre diferentes possibilidades de encontro com o campo da alteridade.
}

Abordar o tema da alteridade na teoria freudiana é legítimo, já que o conceito de inconsciente representa o princípio de alteridade por excelência (Caropreso \& Simanke, 2008; Moreira, 2005).

$\mathrm{O}$ inconsciente expressa a primordial descoberta freudiana sobre o tema da alteridade, mas não podemos confinar as intuições freudianas sobre a alteridade a uma única definição. Podemos encontrar vários sentidos que deslizam e se articulam circunscrevendo um complexo semântico sobre o tema da alteridade na psicanálise freudiana. Freud não tematiza explicitamente o problema da alteridade. Assim, o inconsciente seria o outro exterior e íntimo ao qual estamos mais ligados que a nós mesmos, 
ainda que não queiramos saber nada a respeito disso. Miller (citado por Fernandes, 2000, p. 49) revela que o tema do outro é "tão íntimo que Freud mesmo não o percebe. Tão íntimo que essa intimidade é extimidade. É um mais-além interno".

Assim, pretendemos explicar a importância do tema da alteridade no mito freudiano de fundação da cultura descrito em Totem e tabu.

Trataremos primeiramente da temática da alteridade, discutindo seu conceito e acentuando as contribuições interdisciplinares do campo filosófico. Em um segundo momento, o acento da discussão recairá na proposta de Lévinas acerca da ética que se institui a partir da alteridade. Em um momento posterior, com base na obra freudiana Totem e tabu (1976A) e de outros textos de Freud e de Lacan, destacaremos o processo de encontro com o campo da alteridade apresentado pela relação entre os irmãos e com o Pai totêmico.

\section{Alteridade: vicissitudes de um conceito}

O problema do outro (o reconhecimento da alteridade e sua problematização) pressupõe a tomada de consciência de si por parte do indivíduo, e só pode surgir em sua plena expressão após a consagração do individualismo, constituindo, portanto, um dos temas centrais do pensamento contemporâneo. A relação eu/outro é um acontecimento radicalmente humano, é uma experiência antropológica que se manifesta nas diferentes formas simbólicas da cultura (mito, religião, moral) e que não poderia deixar de se manifestar também na Filosofia. A questão que então se põe é a seguinte: como viver em comum, como construir a comunidade política, a partir do reconhecimento da diversidade dos interesses e opinióes dos indivíduos? Ora, é nesse contexto que o diálogo surge como experiência fundamental da problemática eu/outro, individualidade/alteridade. Por isso o diálogo não foi apenas uma forma de expressão privilegiada por Platão, mas refletiu também o próprio conteúdo de seu pensamento, ou seja, respeito à alteridade. Entretanto, no horizonte do pensamento clássico, da metafísica, a polaridade eu/outro é apenas um momento de uma razão que deve encaminhar-se para a descoberta de uma realidade suprassensível, uma realidade intrinsecamente inteligível e absoluta (Reale, 1994).

Com o advento do cristianismo, reencontramos em novos termos a problemática da relação eu/outro, uma vez que o Deus bíblico-cristão não é uma entidade abstrata, um princípio explicativo das coisas, mas é concebido como um Deus pessoal que se dirige a cada homem em sua 
individualidade concreta. Assim, não é de se estranhar que a filosofia cristã tenha introduzido o conceito de pessoa como um dos fundamentos de sua antropologia (Boehner \& Gilson, 1982).

No pensamento moderno, a primazia do eu é afirmada inequivocamente com o racionalismo cartesiano. $\mathrm{O}$ ponto de partida da reflexão filosófica e a primeira certeza alcançada é a do eu como primeiro existente (cogito) e concebido como sujeito, isto é, como um existente radicalmente diferente de todos os outros. Essa primazia do sujeito e de sua radical diferença em relação a todos os outros entes foi consagrada pelo criticismo kantiano, para o qual todos os entes só podem ser apreendidos como objetos, como manifestações, fenômenos, para uma consciência. $\mathrm{O}$ conjunto do pensamento moderno passou a ser interpretado como incluído no paradigma da filosofia do sujeito e da consciência, na qual impera a imagem da alma solitária pensando sobre suas próprias experiências para, a partir delas, aceder aos outros e ao mundo. São muitos os impasses decorrentes dessa concepção: como o eu em seu isolamento, pensado como uma mônada, poderia conhecer a objetividade do mundo e relacionar-se com o outro? Essa dificuldade foi percebida pelos próprios filósofos modernos como, por exemplo, Kant (1785-1980), que estabeleceu o irredutível reconhecimento do outro como exigência da razão prática, conforme podemos ver na segunda fórmula do imperativo categórico apresentada na Fundamentação da Metafísica dos Costumes: "Age de modo a considerar a humanidade, seja na tua pessoa, seja na pessoa de qualquer outro, sempre também como fim e nunca como simples meio" (Kant, 1974, p. 130).

O que é importante ressaltar é que esse não é um problema marginal no pensamento filosófico, pois inaugura transformações que desaguarão na formação do que passou a ser designado como o paradigma da linguagem e, em especial, em sua versão pragmática. $\mathrm{O}$ paradigma da linguagem apenas demarca o campo das teorias que concebem o sujeito originariamente como ser social, ser-no-mundo, ser-com, enfim, como mergulhado no universo das interaçôes simbólicas.

Com base nessa breve contextualização, no campo da Filosofia, das vicissitudes conceituais da questão da alteridade, perguntamos: como definir alteridade? Segundo Brandão (1986), o diferente é o outro, e o reconhecimento da diferença é a consciência da alteridade. O outro é um diferente e, por isso, simultaneamente, atrai e atemoriza, e o esforço em traduzi-lo e explicá-lo, ou seja, em reduzi-lo a uma realidade viva, implica rejeitar o reconhecimento da diferença. Assim, o outro sugere ser decifrado, mas não reduzido ao mesmo (Brandão, 1986). No momento em que se instaura a possibilidade da relação com o outro, fica em aberto o modo particular como esse relacionamento irá 
se dar. A modalidade mais comum da relação com o outro é a do conflito, da luta mortal, quando o eu se aproxima do outro para escravizá-lo, para reduzilo ao papel de testemunha e de espelho, para reduzi-lo ao mesmo (FrayzePereira, 1994). Nesse caso, ocorre uma projeção de partes desagradáveis do eu no outro e, consequentemente, deve surgir o movimento de purificá-las.

Existe uma modalidade de relação com o outro em que é necessária uma tradução, um deciframento de sua realidade viva para possibilitar a comunicação. Sem essa tradução de códigos, não seria possível o encontro intersubjetivo. $\mathrm{O}$ outro deve ser convidado para sair do campo da pura diferença e aproximar-se de certa familiaridade, criando, pois, condições de possibilidade para a instauração do diálogo. Nessa acepção, o outro se assemelha ao ksénos grego, guardadas as peculiaridades, porque, na experiência pontual grega, o estrangeiro é totalmente familiar.

A herança grega fundamenta uma das formas atuais de trabalhar com a questão da estrangeiridade, pois o outro/estrangeiro pode tornar-se familiar e, assim, ser denominado de ele ou $t u$, colocando, pois, a questão do reconhecimento entre sujeitos, entre $e u$ e $t u$ ou ele. Nesse caso, a dimensão enigmática do outro é esquecida, prevalecendo a equiparação necessária para a lógica da razão comunicativa, para certa estabilidade entre os termos do diálogo. Assim, apresentamos uma segunda modalidade de relação com o outro, na qual não há um aniquilamento radical, mas se processa uma equiparação entre o eu e o outro, transformando este em ele ou tu, e instaurando, pois, a situação dialógica (Teixeira, 2003).

De acordo com os objetivos deste artigo, interessa-nos, sobretudo, uma terceira modalidade, em que o outro guarda a qualidade do enigma, já que tal figura constitui marca da constituição dos saberes e práticas psicanalíticas. Esse aparece como uma realidade enigmática, seja no interior do eu como o inconsciente, seja fora, como o outro sedutor e traumatizante que se apresenta no processo de constituição da subjetividade.

O encontro com a "alteridade" é decisivo na constituição do sujeito, sendo que este se apresenta como um enigma indecifrável. Assim, uma modalidade de relação com o outro não pode ser decifrada, tal como uma ideia, pois ela não se enquadra no campo da intencionalidade, sendo, no entanto é uma experiência eminente.

Acreditamos que o mito freudiano sobre a origem da cultura - Totem e tabu (1976d) - apresenta essas três modalidades de relação com a alteridade. O primeiro momento, representado pelo pai primevo (detentor de todos os bens), representa o campo relacional em que a alteridade é negada; 
após o assassinato do Pai, os filhos estabelecem uma relação de tradução e deciframento, constituindo um segundo momento em relação à alteridade; por fim, a relação com o pai morto apresenta-se como o enigma indecifrável, constituindo o terceiro momento, em que a alteridade passa a ser constitutiva do sujeito e do socius.

Abordaremos, a seguir, com base em Lévinas (1979), a concepção de alteridade, focalizando a consciência não intencional, a passividade, a exposição ao outro e a dívida eterna, pois nos parecem preciosos instrumentos conceituais para a compreensão da dimensão da alteridade no interior da tessitura conceitual de Freud, presente em Totem e tabu (1976d), e também foco teórico de Lacan, em vários momentos de sua obra.

\section{Alteridade em Lévinas: o eu como passividade original}

Para Lévinas (1980), a dialética hegeliana do reconhecimento introduziu o problema da alteridade; essa mesma dialética não poderia, entretanto, manter a sua dimensão de irredutibilidade. Em Hegel, como em Platão, o dialógico, o dialético, é um movimento para a passagem ao absoluto. Esses autores não se interessam pela discussão do reconhecimento no campo concreta do encontro intersubjetivo. Para Lévinas (1980), ocorre com Hegel o que é característico de todo pensamento metafísico: a alteridade é submetida à lógica da identidade; o outro é julgado segundo os cânones do mesmo. Assim, em Hegel, o outro não seria mantido em sua irredutibilidade, mas seria suprassumido no Saber Absoluto. Segundo a leitura levinasiana, a filosofia moderna revelaria o constante privilégio do discurso da identidade sobre a problemática da alteridade.

Para Badiou (1995), foi Lévinas (1980) quem introduziu o "entendimento da alteridade" no seio do pensamento filosófico (Badiou, 1995, p. 33). Podese concordar com Badiou (1995), pois foi Lévinas (1980) quem tematizou explicitamente o problema da alteridade. Todavia, como acentua Fuks (2000), quando Freud propõe o estudo do inconsciente, instaura-se a prioridade do outro no coração da filosofia do eu.

$\mathrm{Na}$ contramão da racionalidade da Aufklārung, ${ }^{1}$ que privilegiava a coerência e a identidade como formas de verdade, a psicanálise se anuncia como um método de escuta do incoerente, do não idêntico e do deformado, obedecendo sempre à lógica do Outro (Fuks, 2000, p. 56).

O termo Aufklärung aparece na filosofia kantiana e é similar à ideia de iluminismo, ou seja, o uso da razão como condição da liberdade e maioridade. 
Lévinas (1997a) é um crítico da filosofia da identidade. Para ele, no "pensamento entendido como visão, conhecimento e intencionalidade, a inteligibilidade significa, pois, a redução do Outro ao Mesmo" (Lévinas, 1997a, p. 207). Na modalidade voluntária da consciência intencional, a sua atividade é mortífera em relação à dimensão do outro. No domínio da consciência, o outro é visado para completar, e o inconsciente é visto como deficiente. Assim, o inconsciente como alteridade escapa ao princípio da intencionalidade e à perspectiva da visão, e deve ser escutado (Moreira, 2003).

$\mathrm{O}$ eu prefigurado pela consciência intencional conhece e representa, e, nesse processo, conhece a si mesmo refletido na realidade objetiva que ele próprio constitui. Assim, seu autoconhecimento é possível mediante a realidade conceitual que não esgota o ser do homem. Quando a consciência toma o próprio eu por objeto, ela capta um princípio não intencional, uma pura vivência que escapa à intencionalidade reflexiva. Essa "consciência" préreflexiva precede a toda intenção; não é ato, mas sim passividade (Lévinas, 1980). Nossa habitação no mundo não pode ser reduzida à intencionalidade de nossa consciência, sendo a representação uma tomada de posição em relação ao objeto. A emoção, contudo, precede a representação. Lévinas (1997a) escreve que a primeira experiência do ser está situada ao nível da emoção, portanto a experiência da passividade precede à arrogância intelectual da consciência intencional, do eu pensante como pura atividade. A consciência pré-reflexiva, não intencional, não poderia ter conhecimento racional dessa passividade, pois a racionalidade exige um eu intencional. $\mathrm{Na}$ sua não intencionalidade, anterior a todo querer e a qualquer falta, a identidade da "consciência não intencional" encontra-se exposta, entregue à exterioridade absolutamente estranha e imprevisível. Segundo Lévinas (1997a), a consciência, antes de significar um saber de si, é apagamento ou discrição da presença, sem intenção. Do fundo da natural insistência do eu, que tem seu direito de ser assegurado, do coração da identidade original do eu, emerge contra essa garantia a exposição passiva ao outro. Lévinas (1997b, p. 77) revela: "O eu, assim entregue ao ser, é lançado para fora de si, para os lugares de um eterno exílio, perde seu domínio sobre si, é superado por seu próprio ser. Está à mercê de acontecimentos que já o determina”.

Assoun (1997) atribui a Lévinas a entrada do Outro na Ética e a Lacan, a promulgação do Outro da Psicanálise, porém podemos vislumbrar que, apesar da importância da leitura lacaniana sobre a alteridade como constituinte do sujeito e do social, Freud, conforme Foucault (1990), em As palavras e as coisas, ergue a psicanálise como um dos saberes que instituem o outro como fundante. Nesse esteio de pensamento, com base na discussão acima sobre a 
complexidade que o conceito de alteridade acolhe e sobre a ética do outro em Lévinas, o acento deste texto recairá em Freud (1976d) e nas implicações que podemos apreender acerca da fratria como espaço alteritário, fazendo apelo, para tanto, às contribuiçôes de Lacan e de leitores das obras dos psicanalistas citados.

\section{O Pai e a fraternidade em Freud: possibilidades de relaçôes alteritárias}

Em Totem e tabu, Freud (1976d) ergue o tabu do incesto como pedra angular da sociedade, constituindo esse temor e seu derivado (a exogamia) marcos da passagem do estado de natureza ao de cultura, ou seja, do ingresso do homem anárquico na ordem social. Como estado de natureza se especula, por uma operação lógica e não cronológica, o momento primeiro marcado pela permissividade total, momento de caos primordial em que não se pode falar de socius, já que não há leis de ordenamento que possibilitem relações sociais estabilizadas e simbolizadas. É claro que é um estado não determinável tanto em termos cronológicos como em termos de suas características, funcionando, porém, como recurso norteador necessário para se poder pensar em um estado de coisas que sirva como referente externo ao que caracterizamos como de civilização e, ou, cultura. Enriquez (1991, p. 30-31) escreve que "é necessário colocar um acontecimento na origem de todas as coisas". Talvez, supomos, seja o que nos permite pensar, a partir daí, em um lugar que comporte tudo que escapa à lógica reinante no momento posterior à marca da origem. Acreditamos que é nesse sentido e sustentados por tal raciocínio que especulamos sobre um estado de natureza no qual reina a violência absoluta, a satisfação plena e imediata das pulsões: "O Tempo primevo só conheceu as relações de força e as relações sexuais” (Enriquez, 1991, p. 30-31).

O alvo primordial desse ato fundador consiste na obstacularização da onipotência característica daquele que antes ocupava o lugar de chefe e que, pelo compromisso assumido entre seus súditos, é dele destituído pelo seu brutal assassinato por esses, passando a ocupar um lugar de Pai, Pai não real, mas mítico. É a partir da impotência dos súditos frente à onipotência absoluta do chefe (detentor de todas as terras e de todas as mulheres), que eles se unem no planejamento e efetivação de um crime, visando a ocupar tal lugar de privilégio. Porém o que sucede ao ato de assassinato é a afirmação da impossibilidade de esse lugar vir a ser ocupado por alguém em particular e, por conseguinte, um reconhecimento e uma tentativa de respeito do outro no seu campo de diferença. A busca pela onipotência, paradoxalmente, coloca-a como necessariamente impossível, propiciando a gênese de uma comunidade 
de iguais (os irmãos se identificam na culpa pelo assassinato) (Freud, 1976d).

O que leva à cultura, portanto, é a confluência da dualidade onipotência do chefe/impotência dos súditos, com a posterior transformação da figura do chefe da horda em Pai (através da irmandade assumida pelo partilhar em conjunto desejos e atos), e o estabelecimento de sua Lei primeira: ninguém mais pode tudo. Somente a partir das leis, agora fundamentais, é que os sujeitos podem se situar. Não é que os irmãos não soubessem que eram frutos da posse das mulheres pelo Chefe despótico, mas, somente após o crime, a paternidade é assumida como função simbólica propiciadora da filiação e, em consequência, da irmandade. Os atos de ter mulheres e fazer filhos, praticados pelo chefe da horda, a nosso ver, não têm a mesma função que o de gerar descendência pela inclusão em uma linhagem de que seu progenitor também participa, o que não é o caso do Chefe: ele não representa nem se submete a nenhuma lei de filiação, já que ele é toda e qualquer lei. Tal passagem se firma pelo pacto fundador que se dá entre os irmãos, o que significa afirmar que esse se faz pela fratria:

A força desse corpo unido opõe-se então como "Direito" à força de qualquer indivíduo, que é condenado como "força bruta". A substituição do poder de um único homem pelo poder de união de alguns constitui o passo decisivo em direção à civilização e na construção de uma nova modalidade de relação com o campo da alteridade. Sua essência reside nas circunstâncias de que os membros da comunidade tenham restringido suas possibilidades de satisfação, ao passo que o indivíduo não reconhecia essas restriçōes. O primeiro requisito de uma cultura é, portanto, a justiça - ou seja, a garantia de que, uma vez estabelecida, uma lei não será quebrada em favor de algum indivíduo (Freud, 1976a, p. 116).

O pai primevo freudiano passa a sustentar o estatuto metafórico de nó instaurador da cultura e da civilização, sendo pelo crime primordial que a Lei universal é inaugurada e engendrada passa a ocupar, assim, o campo da alteridade enigmática e constitutiva do humano.

Assim, toda organização coletiva só pode ser pensada a partir da Lei do Pai e da fraternidade que se torna necessária entre os irmãos. A construção de um reino baseado na abstinência do poder absoluto sobre as mulheres e as terras é fundamento para que se evite a guerra e a divisão do grupo. Portanto o laço libidinal que é abordado em Totem e tabu (1976d) e, posteriormente em Psicologia de grupo e análise de ego (1976c), enfoca a relação entre pai e filhos, e entre irmãos. É importante ressaltar que essas modalidades de sustentação 
da rede social não são firmadas sobre a abolição do ódio como modalidade de violência. Muito pelo contrário, ambas se sustentam na concretização de uma rede social firmada na ambivalência libidinal.

Assumindo a relação entre estado de sociedade e relação fraternal, os processos de identificação se afirmam como essenciais à constituição de qualquer relação social. Pensando em um momento inaugural da cultura, é a identificação dos filhos com o Pai e a identificação deles entre si como irmãos o que sustenta o vínculo que os mantém unidos. A identificação constitui um dos mecanismos que promovem o laço social que se localiza na segunda modalidade de relação com a dimensão da alteridade, a relação de deciframento. Freud (1976c) dedica ao referido processo uma interessante análise acerca da coletividade. A relevância por ele atribuída às massas se dá pelo fato de elas revelarem a condição nuclear da sociabilidade, constituinte do sujeito e do socius em um mesmo movimento.

Para tal aliança, inaugural do social, faz-se necessária uma transformação do lugar dos filhos que, agora, expõem-se como irmãos, instaurando uma relação com os primeiros objetos de amor que não se faz mais no registro da imediatez. É fundamental, portanto, que os sujeitos deixem de se enclausurar na posição de filhos de um pai todo-poderoso, assumindo-se como irmãos. É dessa maneira que é possível se pensar na instalação de uma distância mínima em relação aos objetos primeiros de amor, traço fundante de uma rede fraterna. $\mathrm{Na}$ verdade, a prevalência do amor só é possível pela abstinência ao desfruto ilimitado dos objetos de prazer, sendo esse o preço que os irmãos têm de pagar para que uma formação social, que lhes assegure a vida, seja instalada. Para a psicanálise freudiana, o amor e o ódio constituem os princípios de formação das associações humanas. É devido a Eros e seu poder unificador que os grupos podem ser constituídos.

A psicanálise, portanto, propõe a possibilidade da rede social a partir da consideração estruturante da função do Pai e da identificação dos irmãos entre si e em relação a esse lugar vazio. Tal lugar, antes monopolizado por Um, funciona como operador da função de castração, pela qual ninguém é mais detentor supremo de privilégios. Aliás, a abolição dos privilégios por um sujeito corresponde à instauração mesma da fraternidade.

Enfatizamos que tal construção mitológica anuncia formalmente o desamparo humano, já que é a partir do outro, antes não reconhecido como tal, que se constituem o sujeito e o socius, concomitantemente, em um mesmo movimento. A brutalidade e a violência do desamparo, entendido em termos psíquicos e sociais (inevitável pela precariedade vital do homem), é o que 
irrompe, levando à abertura para o semelhante. A experiência da impotência e do desamparo de que padece o homem do nascimento à morte leva ao movimento de idealização do Outro e do outro como passível de acolhê-lo e de garanti-lo. Contudo, esse diferente, mesmo sendo magnificado, ocupa também o lugar de quem persegue. É sempre ambivalente a relação de que Freud fala: aquele que protege é quem persegue e amedronta. É o sofrimento permanente e a constante lembrança da insuficiência primordial pela ameaça da finitude que marca a aliança entre homens, daí o desejo de apontar sempre para a proteção contra o sofrimento e a morte, bem como para o alívio da culpa (Freud, 1976a). É pelo pacto primordial que o sujeito e o social se constituem, tendo a operação da Lei primordial a função de corte, de separação, de proibição: é o Édipo freudiano (a pedra angular da estruturação intrapsíquica e do processo civilizatório).

Categoricamente, a Lei primeira firma-se não degradando ou aniquilando o desejo, mas estruturando-o, integrando-o no circuito de intercâmbio social. $\mathrm{O}$ processo de corte à onipotência ergue-se como o modelo por meio do qual é possível qualquer articulação desejante irrevogavelmente impelida pela falta de um objeto satisfatório. A satisfação total é proibida (desde e para sempre) para que se constitua o humano. É pela função do Pai nos mitos de Édipo e de Totem e tabu que Freud (1976b) ergue a falta como mitológica, o que sempre supõe, como assegura Lacan, o "desejo ao segundo grau, desejo de desejo" (Lacan, 1991, p. 24), já que o incesto fundamental (o incesto filho/mãe) está para sempre interditado: "O desejo pela mãe não poderia ser satisfeito, pois ele é o fim, o término, a abolição do mundo inteiro da demanda, que é o que estrutura mais profundamente o inconsciente do homem" (Lacan, 1991, p. 89). A posição do Pai sempre nos alerta, seu Nome inscreve-se perpassando a cultura e o sujeito. Assumidas essas questóes, fica claro o porquê de Freud (1976b, 1976c, 1976d) não diferençar a psicologia do indivíduo da psicologia das massas. Pensar a psicanálise como ética supõe a afirmação de que o sujeito é social.

A problemática da possibilidade do socius pode, então, ser entendida em função da tendência narcisista que imprime a marca do rechaço ao diferente. A dificuldade sempre marcará os laços sociais, laços sustentados pela ambivalência afetiva, já presente em Totem e tabu (1976d). É a perenidade do desejo violento de parricídio pelo desejo violento de incesto que funda o laço social pela possibilidade de filiação, já que, seguindo o mito freudiano, os irmãos só podem assim ser chamados quando o chefe da horda se transforma em Pai Morto, em Pai Mítico: é o desejo de morte, o assassinato, o repasto totêmico, a culpabilidade e a renúncia à guerra total que os fazem irmãos. 
Somente podemos falar em grupo regrado e coeso, pelo compromisso de todos de não se tornarem o chefe, o Um de antes, mas de abrirem mão de certos desejos e, assim, poderem realizar outros. Enfim, é pela violência que a renúncia à onipotência faz aliança.

A entrada na cultura é, assim, marcada pelo signo da perda, da falta; sendo o programa de ser feliz irrealizável. Isso não quer dizer que a cultura só possa ser dita pelas terríveis restrições que traz à sexualidade e à agressividade. Ela impõe, certamente, suas rigorosas condições, que são o que a possibilita, como também, concomitantemente, o sujeito. A convivência permite vínculos, apoio, reforço e, principalmente, o amor e o trabalho - seus progenitores: a cultura é fruto de Eros, do desejo de coesão, de união, de ligação, de constituir unidades cada vez maiores (Freud, 1976a).

\section{Considerações finais}

A história da cultura é, portanto, a história própria da alteridade inaugurada pela violência do apelo irredutível do outro. É pelo Outro que o sujeito se reconhece como tal. O outro não lhe é agradável, porém é imprescindível; significando essa abertura para a alteridade uma exigência de Eros que, conflitando para sempre com as pulsões de morte, possibilita o campo no qual o movimento de disrupção engendra a radicalidade do diferente, do singular, do excêntrico, do raro, do extraordinário (Freud, 1976b).

A leitura de Totem e tabu (Freud, 1976d) se favorece com o uso de noçôes como aliança, troca, violência, dívida, culpa, compromisso, promessa, uma vez que estas colocam em cena modalidades de relação alteritária. Em se tratando das implicações da submissão à alteridade como central para a constituição dos saberes e práticas das psicologias, Figueiredo (1994), apoiado nas concepções levinasianas, alerta-nos sobre o fato de que o cuidado com o ser do outro que há em si representa o fundamento da prática ética da hospitalidade, na qual a estrangeirice freudiana é condição para quaisquer possibilidades de intervenção junto ao padecimento do outro, o que supõe a disponibilidade ao diferente, ao estrangeiro que nos habita.

A alteridade, como fundamento da existência, quando rechaçada implica em efeitos mortíferos dos pontos de vista singulares e coletivos, implicações essas que se estendem à rede social e aos laços que, para além de meros vínculos interpessoais, assujeitam-nos à lógica da Lei e das leis, isto é, às funçôes paterna, materna e fraterna. Quando se rompem tais 
condiçôes de vida subjetiva, o estrangeiro constitui o bárbaro com o qual não mantemos olhares identificatórios e identitários, constituindo-se por outra língua, por outro território e por outra temporalidade, não somente alheias e estranhas, mas impermeáveis ao outro. À refutação da diferença corresponde o esgarçamento e, até mesmo, o rompimento do laço social. Tais modalidades de pertença social constituem tema de preocupação de psicanalistas que se debruçam sobre a fragilidade da rede social na atualidade, na qual imperam a exacerbação do individualismo, do narcisismo e do hedonismo (Alberti \& Figueiredo, 2006; Melman, 2002).

Acolher a alteridade como especificidade constitutiva do humano acalenta-nos por crermos que constitui um antídoto contra a angústia do desamparo e de suas figuras contemporâneas. Em se tratando especificamente do campo das intervençôes em saúde mental, destacamos que a ética do cuidado se baseia no acolhimento da estrangeirice que nos faz humanos, desse estofo a respeito do qual sabem os poetas e artistas (Teixeira, 2009). E como revela Lévinas (1980), estamos primordialmente vinculados ao outro, mesmo que essa experiência tenha ocorrido para uma consciência pré-reflexiva. O vínculo ao outro é estrutural e estruturante para o sujeito; matar o outro é cometer suicídio.

Em Totem e tabu (Freud, 1976d), portanto, encontramos as três modalidades básicas de relação com o campo da alteridade, tal qual abordadas por Brandão (1986). Isso nos possibilita pensar acerca das implicações teórico-clínicas daquelas para a consolidação de leituras psicanalíticas sobre os modos de constituição subjetiva na atualidade, especialmente quando as fazemos dialogar com a filosofia de Lévinas, autor que ergue o conceito de alteridade como fundamento da existência. Nesse sentido, quanto ao incremento às leituras psicanalíticas em interface com outros saberes e práticas, citamos Moreira (2003), em relação às implicações à vida cotidiana:

O homem busca formas alteritárias que possam tornar compreensível sua vivência. Os mitos, as religiōes e as ciências representam "alteridades" na forma de sabedorias que organizam, fornecem sentido e compreensibilidade às experiências humanas. A psicanálise integra esse grupo que nomeamos como "alteridades abstratas", que possibilita aos sujeitos, através de uma forma de saber, uma possível compreensão sobre a sua vivência (Moreira, 2003, p. 264).

É com o propósito de ratificar o lugar de fundamento da alteridade que acentuamos que Freud pode nos servir de guia para as reflexões acerca das árduas posiçôes que ocupamos diante do estranho. Estranho esse que, 
embora visto no outro, nos habita e nos faz participar da coletividade de humanos, tal qual a filosofia de Lévinas, por outras premissas e percursos metodológicos, acentua.

\section{Referências}

Alberti, S. \& Figueiredo, A. C. (2006). Psicanálise e saúde mental. Rio de Janeiro: Companhia de Freud.

Assoun, P. L. (1997). O sujeito e o outro em Lévinas e Lacan. Cadernos de Subjetividade, 5 (1), 91-116.

Badiou, A. (1995). Ética: um ensaio sobre a consciência do mal. Rio de Janeiro: Relume Dumará.

Boehner, P. \& Gilson, E. (1982). História da Filosofia Cristã. Petrópolis: Vozes.

Brandão, C. R. (1986). Identidade e etnia: construção da pessoa e resistência cultural. São Paulo: Brasiliense.

Caropreso, F. \& Simanke, R. T. (2008). Uma reconstituição da estratégia freudiana para a justificação do inconsciente. Agora, 11 (1), 31-35. Recuperado em 20 de agosto de 2009, de http://dx.doi.org/10.1590/S151614982008000100003.

Enriquez, E. (1991). Da Horda ao Estado: psicanálise do vínculo social. Rio de Janeiro: JZE.

Fernandes, L. R. (2000). O olhar do engano: autismo e outro primordial. São Paulo: Escuta.

Figueiredo, L. C. M. (1994). A questão da alteridade na teoria da sedução generalizada de Jean Laplanche. Psicologia USP, 5 (1-2), 297-308. Recuperado em 15 de outubro de 2009, de http://www.revistas.usp.br/psicousp/article/ view/ 34503/37241.

Foucault, M. (1990). Les mots et les choses. Paris: Gallimard.

Frayze-Pereira, J. A. (1994). A questão da alteridade. Psicologia USP, 5 (1-2), 11-17. Recuperado em 15 de outubro de 2009, de http://www.revistas.usp. br/ psicousp/article/view/34486/37224. 
Freud, S. (1976a). Mal-estar na cultura. In S. Freud. Edição standard brasileira das obras psicológicas completas de Sigmund Freud (Walderedo Ismael de Oliveira, Trad., Vol. 21, pp. 75-174). Rio de Janeiro: Imago. (Trabalho original publicado em 1930.)

Freud, S. (1976b). O estranho. In S. Freud. Edição standard brasileira das obras psicológicas completas de Sigmund Freud (Walderedo Ismael de Oliveira, Trad., Vol. 18, pp. 273-319). Rio de Janeiro: Imago. (Trabalho original publicado em 1919.)

Freud, S. (1976c). Psicologia de grupo e análise de ego. In S. Freud. Edição standard brasileira das obras psicológicas completas de Sigmund Freud (Walderedo Ismael de Oliveira, Trad., Vol. 18, pp. 89-181). Rio de Janeiro: Imago. (Trabalho original publicado em 1921).

Freud, S. (1976d). Totem e tabu. In S. Freud. Edição standard brasileira das obras psicológicas completas de Sigmund Freud (Walderedo Ismael de Oliveira, Trad., Vol. 13, pp. 13-168). Rio de Janeiro: Imago. (Trabalho original publicado em 1913.)

Fuks, B. (2000). Freud e a judeidade: a vocação do exílio. Rio de Janeiro: Jorge Zahar.

Kant, I. (1974). Fundamentação da metafísica dos costumes. In I. Kant. Os pensadores. (pp. 101-162). São Paulo: Abril Cultural.

Lacan, J. (1991). A ética da psicanálise. Rio de Janeiro: JZE.

Lévinas, E. (1979). Le temps et l'Autre. (Ulpiano Vázquez e Edgar Piva, Trad. Livre.) Paris: Fata Morgana. (Trabalho original publicado em 1947.)

Lévinas, E. (1980). Totalidade e infinito. Lisboa: Edições 70.

Lévinas, E. (1997a). A consciência não intencional. In E. Lévinas. Entre nós: ensaios sobre a alteridade. (pp. 165-177). Petrópolis: Vozes. (Trabalho original publicado em 1983.)

Lévinas, E. (1997b). Lévy-Bruhl e a filosofia contemporânea. In E. Lévinas. Entre nós: ensaios sobre a alteridade. (pp. 66-83). Petrópolis: Vozes. (Trabalho original publicado em 1957.)

Melman, C. (2002). L'homme sans gravité. Paris: Denoel. 
Moreira, J. de O. (2003, julho/dezembro). Do problema da alteridade no pensamento freudiano: uma construção. Ágora, 6 (2), 251-270.

Moreira, J. de O. (2005, agosto). A alteridade no enlaçamento social: uma leitura sobre o texto freudiano "O mal-estar na civilização". Estudos de Psicologia, 10 (2), 287-294.

Reale, G. (1994). Platão e Aristóteles. In História da Filosofia Antiga (Vol. 1). São Paulo: Loyola.

Teixeira, L. C. (2003, abril). Ética e subjetividade: indagações em Habermas e Rorty. Estudos de Psicologia, 8 (1), 147-153.

Teixeira, L. C. (2009). Freud e a literatura: destinos de uma travessia. Fortaleza: As Musas. 